\title{
Use of Innovative Forms of Teaching Students to Create Business Discourse
}

\author{
Novikova Natalia Gennadyevna ${ }^{1}$, Zorina Natalia Mikhailovna ${ }^{1} \&$ Kortunov Vadim Vadimovich ${ }^{1}$ \\ ${ }^{1}$ Russian State University of Tourism and Service, Moscow, Russia \\ Correspondence: Novikova Natalia Gennadyevna, Russian State University of Tourism and Service, 141221 \\ Moscow, Russia.
}

Received: December 18, 2014 Accepted: January 20, 2015 Online Published: April 28, 2015

doi:10.5539/ies.v8n5p240

URL: http://dx.doi.org/10.5539/ies.v8n5p240

\begin{abstract}
This article highlights an important role of speech studies disciplines in teaching students to create business discourse, stresses practical orientation of teaching, a need to achieve a greater and more effective balance of theory and practice. The article presents innovative forms of teaching students to create and percept institutional business discourse, notably to model speech situations close to a real communicative situation; to develop and analyze verbal behaviour scenarios, analyze speech situations, reflecting communication needs, discursive matrices. In the article we emphasize that use of speech situations and situational problems, close to real life during training, will allow transferring the student from a learner's position to a researcher's position and enhance his/her creativity, contribute to development of intellectual abilities.
\end{abstract}

Keywords: speech situation, communicative situation, situational problem, frame, discourse, discourse, discourse-analysis, discursive matrix

\section{Introduction}

Transition of higher educational institutions of Russia to the new federal standards, which are based on a competence approach, is primarily associated with increase of practical orientation of education. In this regard, in our opinion, the discipline "Technologies of Business Communication" present great opportunities, it is delivered in FSEI HVE "Russian State University of Tourism and Service", and within the framework of which in order work out practical communication skills, teachers use innovative forms of teaching, including business games, modelling communicative situations, situational problems, which are an effective tool for teaching, not only in high school, but also in business. Formation and development of communicative competence of students, on the basis of creation and perception of monologic and dialogic discourse and using interactive forms, should be an integral part of methodological organization of social and human sciences, especially those relating to speech studies. In this regard, a growing interest in creating modern scientific and methodical literature, concerning issues of communicative linguistics, linguistic pragmatics, paralinguistics, etc.

\subsection{Importance of the Topic}

Currently, teachers of speech studies disciplines ascertain a low level of basic language, speech and communicative competence of students. We can identify a whole range of reasons which determined the low level of linguistic knowledge and students' skills to a greater or lesser extent. However, we must once again emphasize that spiritual condition of the modern society is vividly reflected in young people's speech, which is distinguished by a primitive individual vocabulary, hackneyed phrases, unjustified deviation from the language rules, etc. However, the student and the graduate should be able to competently and convincingly express their thoughts, to build a highly qualified professional communicative speech for providing industrial and economic activity. Language development reflects a level of students' intellectual abilities. Didactic material used in teaching professional speech, should be selected to, first of all, develop thinking, and not only to contribute to mechanical treatment of any operation. A variety of standard and custom speech situations frames should be presented at lectures, and it needs to be worked out at practical lessons. The greater the number of frames is qualitatively learned by students, the higher the level of discursive competence and, consequently, communicative competence. The use of innovative learning techniques (in particular, modeling speech situations close to a real communicative situation, development and analysis of speech behaviour scenarios, analysis of speech situations, which reflect communication needs) will contribute to solving an important methodological 
problem-to improve communicative and, consequently, professional competence of students (Zorina \& Kortunov, 2014).

\subsection{Main Provisions}

Achievements of linguistic pragmatics, in particular the theory of discourse that orients a learning process to a multi-faceted communication of speech practice of students with real life, on account of diverse communication situations, have special didactic significance in current conditions of teaching students of non-language higher education institutions to the culture of Russian speech, namely professional speech. The theory of communication science is involved in lectures not to load erudition of students, but to the extent and with the intention so that it successfully works for practice of teaching professional speech, for recognition of its rules and acquisition of required communicative skills be learners-full perception and full production of professional speech. From this point of view, the review of concepts also includes all kinds of concepts of communicative competence which are didactically useful (language, speech, discourse ones, intercultural et al.), the concept of discourse, discourse-analysis, the notion of speech/communicative situation and its components, the concept of "linguistic identity", "verbal strategy," "speech tactics" and others.

The situational principle is one of the main principles in teaching students the communication rules, verbal strategies and tactics, communication technologies. Almost all methodists note a special role of the speech situation in the learning process. In particular, Passov defines the speech situation as a dynamic system of learners' relationships, which is, due to its reflection in the mind, generates a personal need for purposeful activity and feeds this activity. Analysis of relationships enables a scientist to identify their determinants and types: status, role, activity and moral ones. Leontyevgives a somewhat different interpretation of the term "speech situation": "... Set of verbal and non-verbal conditions, which are necessary and sufficient to carry out a verbal act according our made plans-whether conditions are given in the text or set up by a school teacher". Building on provisions of Leontyev and Izarenkov presents the speech situation as a set of conditions, which identifies the target and the executive side of its corresponding speech act, i.e. a deep structure of meaningful statements. A speech act, according to Izarenov, is a statement of any person, drawn up as a sentence or a combination of several sentences addressed to another person and which makes him/her to response. A communicative aspect of a speech situation is highlighted by Formanovskaya, which understands a communicative (speech) situation as a complex set of external conditions of communication and internal conditions of people who are talking, presented in a speech production - saying, discourse. This complex, on the one hand, generates speech, and on the other hand - is reflected in speech in its essential components. We pay so much attention to a speech situation due to its functional load (Leontyev paid attention at it as well): we will be interested in a speech situation 1) as one of components of communicative competence, 2) as a way of presentation of language material, 3) as a way of organizing creative works of students. Speech behaviour is determined by a speech situation, task, terms of communication and communication needs. Speech behaviour was interpreted by Shchukin as "a form of human interaction with the environment". Harchenko presents verbal behaviour as "verbal behaviour of individuals in given circumstances, which reflect specificity of language existence of a speaking group in the given social system", and analyses models of verbal behaviour in a professional sphere. A number of researchers identify speech and communicative behaviour, at the same time emphasizing different accents: speech-inherent to speech behaviour and communicative-reflecting norms, rules of communication. The concept of "communicative behaviour", in our opinion, is certainly wider than the concept of "verbal behavior" (Kortunov, 2013). Sternin and Prohorov present communicative behaviour as behaviour (verbal and non-verbal one accompanying it) of a person or groups in the communication process, which is regulated by communication norms and traditions of the given society.

Significance of a situation as a condition of business communication cannot be overestimated. By modeling and analysing a particular communicative situation, distribute it into components, students under the guidance of a teacher even before analysing a content of a discourse have a general idea of main participants of communication, topic of communication, intentions of the speaker and can assume a probable reaction of the listener. Thus, an analysis of the communicative situation provides an opportunity to prepare the student for creating professional discourse.

\section{Methods}

In this work we used methods of generalization, classification, analogy, modeling; a system of discursive matrices, discourse-analysis, analysis of scientific and educational materials on the topic of research.

\section{Results}

When teaching students to create and percept institutional business discourse, along with traditional forms of 
learning, innovative forms should be widely used: modeling of speech situations close to a real communicative situation; development and analysis of speech behaviour scenarios, analysis of speech situations, which reflect communication needs, use of discursive matrices.

\subsection{Practical Value}

This article proposes a specific linguo-didactic material and its methodological comment, which can be used in the final or a modified form in actual teaching of the courses "Russian language in professional communication", "Speech Communication", "Technologies of Business Communication" and other university speech studies disciplines during developing curriculum, teaching aids.

\subsection{Educational-Methodical Support of the Course "Technologies of Business Communication"}

Educational-methodical support of the course "Technologies of Business Communication" which is delivered in FSEI HVE "RSUTandS" is still developing. It is based on teaching literature in psychology (except for the textbook of Zaretskaya) and speech studies disciplines of the humanities cycle, which, by providing a methodological solution to many issues, primarily rhetoric (textbooks, manuals of Vvedenskaya, Pavlova, Golub, Ippolitova, Lvov, Smelkova, Ladyzhenskaya, and Sternin et al.), culture of the Russian speech (textbooks, manuals Akishina, Balykhina, and Ippolitova et al.), is not focused enough on communicative and pragmatic training of students in teaching professional speech. The basis of the course "Technologies of Business Communication" (in terms of speech communications) is a theoretical concept based on the communicative pragmatic approach to description of a language. Taking the following concept as a basis, in which acts the dominant is a linguo-rhetorical component, developed by Romanova and Filippov and a linguo-discursive component, which received coverage in the textbooks of Formanovskaya, which are dedicated to communication and pragmatics, we propose to strengthen practical orientation of the course by identifying the linguo-discursive component as the dominant.

The theory of discourse, discourse-analysis, which are developed and included in the scientific use within western scientific schools, are being developed in works of reputable Russian scientists Borbotko, Formanovskaya, Prohorova, Sedova, Zolotova, Issers, .Karasik, Krasnyh, Makarov, Vinokur, Olyanich, Romanova, Sternin, Filippov, Harchenko and many others, the works which we consider from the point of view of utility, importance for solution of didactic problems in teaching professional speech.

\subsection{The Use of Innovative Forms of Teaching}

In addition to traditional forms of teaching (lectures and practical exercises that are designed to equip students with knowledge in the field of professional communication skills and an ability to use this knowledge in practice and in which priority is given to status-oriented discourse), our proposed training model includes an innovative system of discursive matrices, consisting of three subsystems, or three matrices, each of which is represented by a certain type of business discourse and a choice of genre stereotypes (frames), by practising which a learner masters the relevant communicative skills. Proficiency in a wide range of discursive genres of institutional communication, genre norms and their language resources significantly increases a level of communicative competence of the student. Within the matrix and, consequently, one or another speech genre, teaching strategies and tactics of speech behaviour, further development of written and oral forms of speech is provided. The paper presents a methodologically sound system of appropriate exercises, which help to solidify communication knowledge, skills of students, preparing for a profession related to services, including a variety of situational problems, the content of which reflects interpersonal, production and economic, financial relations, arising during business communication in the field of tourism and service.

\subsection{Teaching Experiment on Introduction the Discourse Theory and Discourse-Analysis}

Teaching experiment on introduction the discourse theory and discourse-analysis, which was held at the Russian State University of Tourism and Service for a number of years, into teaching students professional speech, shows a positive trend in development of communicative knowledge and skills of students to build a highly qualified professional speech. Results of the teaching experiment demonstrate a higher level of discursive competence of students in the experimental group, which is manifested in the ability to model and evaluate a communicative situation and its components, to create real business discourse, revealing a spatio-temporal model of reality, a world view in it and at the same time controlling perception of a listener.

\section{Discussion}

As a part of standard and non-standard communicative situations, we offer situational problems to students, a solution of which will contribute to more effective training of future professionals for working in the "contact zone", including at various forums, methods of emotional and psychological impact of speech and the likely 
psychological reaction, interaction with experts in the tourism and service industry on customer service. By solving a situational problem and, accordingly, by modelling and playing around with a particular situation (for example, tour operators cooperation problems, health insurance problems, discussion and resolution of conflicts related to a breach of contract (failure to provide full excursion services, downward changes in living conditions, increasing prices of tourist products, etc.), communication with customers at the level of tourist products sales, in the process of providing travel services), the teacher shows students interaction of specialists in various companies in the tourism industry in customer service; communication between a client-travel agent-tour operator of a sending party-tour operator of a receiving party; reveals basic functions of travel agencies and tour operators.

Like any problem, a situational problem has conditions-data of communicative situation components (an organizational component, including designation of the speaker, listener, time and place of a speech/communicative act; a thematic component-designation of a topic-and a intentional component-determination of intentions, an intention may be specified by a problem conditions, and it can be omitted)-and finally, a question or a task-for example, determining speech tactics in conditions of talks prolongation. When teaching students business and public discourse, it is necessary, in our opinion, to pay particular attention to the thematic component of a communicative situation, to choose topics that are relevant for participants of economic production and economic activity in the service sector (presentation of products (goods, services, projects); violation of consumer rights; revocation of license for execution of works (services), a change in the commodity-money matrix, etc.) as part of a broad body of speech genres (speech to employees, shareholders, partners, customers/consumers, business conversations, meetings, negotiations; television interviews, etc.). We propose various kinds of discourses as examples, namely: monologic business discourse (speeches of public and political figures, specialists in various fields of activity, including entrepreneurs, as well as speeches, prepared by students); dialogic business discourse (business negotiations, television interviews, etc.); communicative and accompanying business discourse (internal documentation of an organization, business correspondence). Selection of grammatical and syntactical structures is carried out depending on a form of speech (dialogic, monologic, oral and written); on a sphere of communication (economic, legal, technological activity); on a speaker' attitude to the subject of speech, to a listener, to reality.

In selection and presentation of discourses we use basic provisions of the works of Borbotko V. G., Vinokur T. G., Karasik V. I., Krasnyh V. V., Makarov M. L., Prokhorov Y. E., Romanova N. N., Sedov K. F., Sternin I. A., Sidorov E. V., Formanovskaya N. I., Filippova A. V., Shiryaeva T. A. and others.

Students under the guidance of a teacher can make professional speeches as well, and model, analyze scenarios of business conversations, write business letters, etc. As part of situational problems various types of exercises can be used, language and substitute and speech exercises, by doing which students will acquire practical skills and abilities, necessary for specialists to work in a "contact zone".

On an example of situational problems, associated with negotiations as a fairly complex form of business communication between interlocutors who have necessary authority given by their organizations (institutions, firms, etc.) to establish business relations, contracts, to settle disputes or develop a constructive approach to solve them, the article presents a discursive matrix, containing a certain arsenal of linguistic resources required to achieve a communicative result-to conclude an agreement/compromise and to demonstrate their own positive image. The matrix provided us can be produced on a business conversation with relevant amendments, etc.

In addition, given the fact that a large number of students are currently studying in higher education institutions of Russia, the students who are from countries which form the post-Soviet space and who understand the Russian language, but speak it bad, then, in our opinion, the most effective form of teaching foreign students culture of the Russian language and in particular the professional speech both at classes of Russian as a second language and classes of humanitarian cycle disciplines, is by using the presented discursive matrices.

Currently, in many textbooks on speech studies disciplines such as "Fundamentals of Speech Communication," "The Russian language and culture of speech", "Rhetoric", the authors present speech structures, which can be used in various forms of business communication. However, we emphasize a generalizing character of discursive matrices: reproducibility of a discourse, individual language formulas, statements that will be set in linguistic consciousness of students, as well as specific (standard/non-standard) situations; construction of structurally identical speech units, finally, ease of use of the present method. Discursive matrices provide a teacher with an opportunity to be more effective in teaching students the basic genre and linguistic norms of speech, speech strategies and tactics, professional vocabulary-in other words, firstly, an increase in language competence of students. 


\subsection{System of Discursive Matrices}

The word "matrix" is of Latin origin, and enters the Russian language through the intermediate language (German) and in translation from German. Matrize means: uterus, source, and beginning. The lexical meaning of the word is recorded in linguistic dictionaries: 1) One of the main parts of a stamp with a deepening or an opening corresponding to a shape of the work piece, which includes a punch. 2) Polygraph. A deepened mold for casting typesetting letters and stereotypes for manufacturing a set in typesetting machines. 3) Mat., inf. A table arranged in a rectangle of some mathematical objects (numbers, algebraic expressions). Matrix-like-in a form of a matrix (in 1-3 meanings), related to matrices.

Currently, the term "matrix" is little used in linguistics. Professor Borbotko was one of the first people to use the term "matrix" in linguistics. Borbotko defines a matrix as a structural basis of a complex linguistic unit; a method of organization, a scheme for constructing units with identical structures.

We understand the term "matrix" as morphogenesis, including typical speech patterns, corresponding language stemmata and with an ability to reproduce separate language formulas, sentences, discourses, which will be set in linguistic consciousness of students. We understand a language stemma, the same way Professor Borbotko V.G. does, as a dynamic constant, which is the base value for reproducing speech in an unchanged or in a modified form, which gives new models, which, in their turn, are set in linguistic consciousness as stemmata. A matrix consists of frames. Makarov in the fundamental work devoted to discourse "Fundamentals of the theory of discourse" defines a frame as a cognitive structure in a phenomenological field of a person, which is based on a probabilistic knowledge of typical situations and related knowledge of expectations about properties and relations to real and hypothetical objects. In other words, in memory of a person, in this case in memory of a student, knowledge about different types of situations and appropriate language resources is stored as a frame.
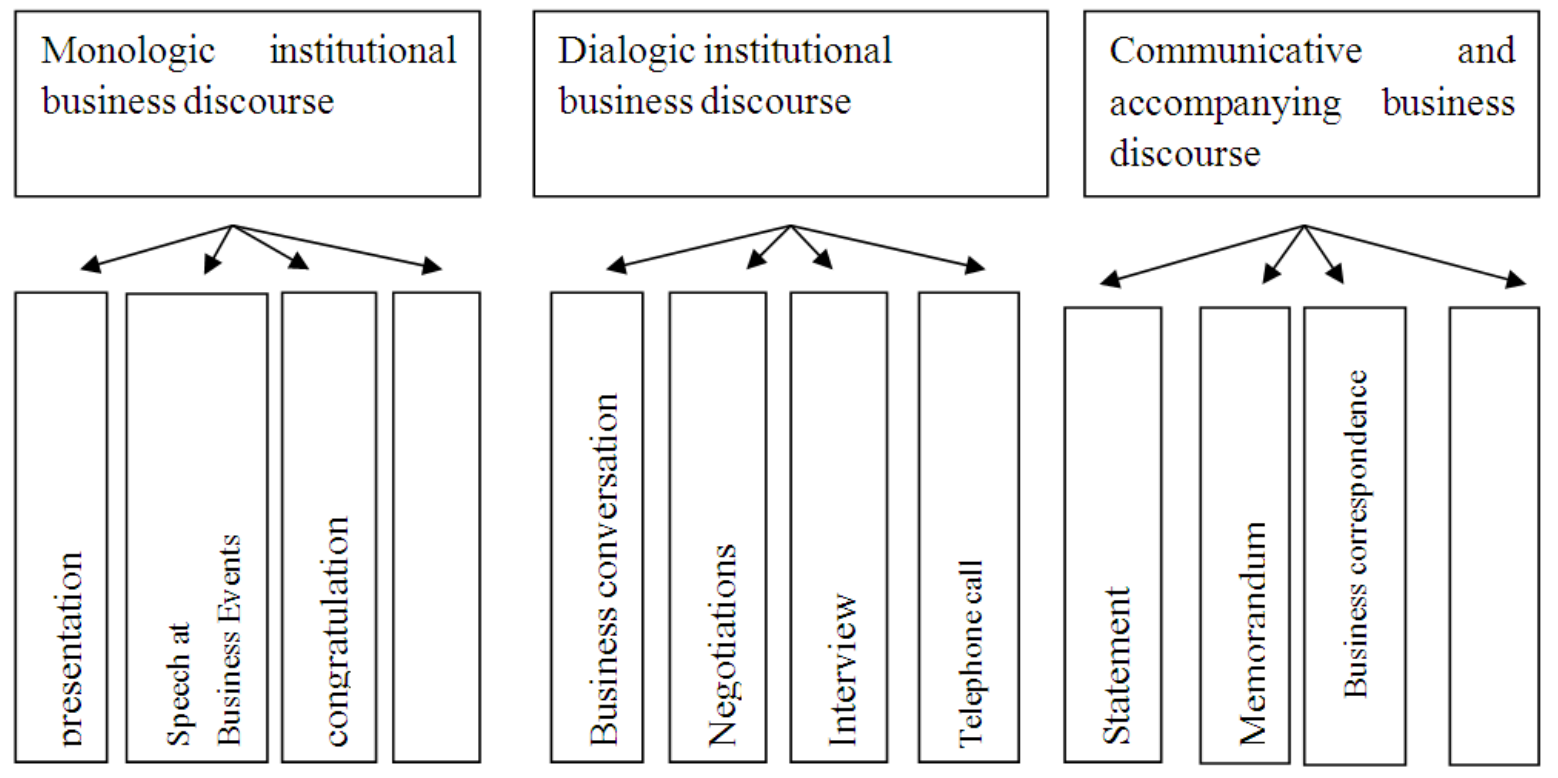

Figure 1. Matrix "Institutional business discourse"

We present our discursive matrix "Negotiations", which, in turn, is a component of the matrix "Dialogic institutional business discourse." The discursive matrix "Negotiations" consists of 3 frames (a number of frames is conditional). Frame No.1 (making contact) includes etiquette formulas of addressing, gratitude; it can be supplemented by etiquette formulas of greetings and speech constructions for introducing participants of business communication. (For example, On behalf of the company, we thank you for your interest in activities of travel agencies. On behalf of the company, let me thank you for your interest in development of tourism business. Let me introduce you to the participants of negotiations. Let me introduce myself. I...-On behalf of the company...let me introduce participants of negotiations).

Note that each of the frames has a language model, and they, in turn, language stemmata. The student under the guidance of a teacher selects an appropriate frame of a language model. This choice is not a mechanical 
reproduction of a particular language formula, because the student must take into account a communicative situation: who says? When says? To whom says? Where says? What says?, i.e. it is necessary to take into account the addressing factor of speech, as well as time, place and purpose of a speech (communicative) act. Thus, a certain genre stereotype is gradually created in communicative consciousness of students; however, this stereotype should not be understood as a frozen form, as mechanical memorization of one scheme: this is a kind of frame consisting of language models, appropriate language stemmata, required for use in a certain communicative situation. The student, by choosing the most appropriate language means from a synonymous row to achieve a communicative goal and using a discursive matrix, will creatively interpret his/her choice of a language model. Frame No.2 (main phase-dialogue-determination/identification of positions, interests) contains speech structures, reflecting an opponent's position and representing certain speech tactics. For example, consider a tactics - accepting a part of the opponent's proposal - which can be implemented verbally in various models (Basically we agree with you. In general, we share your positions. We agree with almost all points of the contract, but would like to return to the discussion...of paragraphs of the contract. In principle, we agree with the proposed conditions, but we have notes...). The teacher can complement various speech tactics that are shown in the classifications, proposed by such scholars as Berdichevsky, Borbotko, Issers, Sedov, Krasnyh, Makarov, Vinokur, Prohorov, Sternin, Romanova, Filippov, Formanovskaya et al., with language models and put them in the corresponding frames. Frame No.3 (final phase-closing of the contact) includes etiquette formulas of gratitude (On behalf of our company let me thank you and say that we are looking forward to further cooperation...).

\subsection{System of Exercises}

For the purpose of practical orientation and teaching students communication skills that are in demand in professional activities, exercises are performed with involving existing, actually operating companies (firms, organizations) or modeled in a similar way. Here are some examples of exercises within the matrix-Communicative and accompanying discourse. 1) Model a communicative situation and write a letter of complaint for failure of a partner company to comply with terms of the contract (delivery of defective goods, volume and terms of delivery, packaging, labelling, payment, downgrade, etc.). 2) The company under examination received a letter of complaint for failure to comply with terms of the contract (delivery of low-quality goods, volume and terms of delivery, packaging, labelling, payment, downgrade, etc.). Prepare an answer. 3) You need to book a hotel room for a head of the company under examination, who is going for 3 days to Prague (Czech Republic). Prepare a letter requesting reservation in a corresponding hotel, a booking confirmation letter, a letter of cancelling the booking.

Matrix models-monologic institutional business discourse-have one and the same scheme, i.e. a stereotype verbal behaviour is formed, which contains stable, passing from one model to the other one language formulas, grammatical constructions. Working with models forming the matrix, a learner masters a certain set of genre frames and therefore knowledge of genre norms and an ability to use this knowledge in a particular discourse. For didactic purposes, for working out and setting certain communication units, we have developed and present the exercises, which are performed in a classroom and help to consolidate skills of analysis and evaluation of a communicative situation, selection of language means, adequate communicative situations, arguments, argumentative activities that contribute to formation of skills related to creating a separate discourse; knowledge of genre frames and an ability to use this knowledge in an actual discourse. These exercises are creative and, above all, develop mental operations of abstraction, synthesis, analysis, etc. On the one hand, the student is offered a sample, a stereotype; on the other-a creative search of a way out of a standard/ non-standard situation and expression through discourse, created on behalf of a one or another speaker (the student, by creating a discourse, plays different social roles), his/her own "I", personal and individual assessment of reality and a status-role function. For example, 1) Model a communicative situation: a) presentation of products, technologies, project, organization; b) staff meeting devoted to the issue of staff reduction due to reduced production, mergers, etc. c) shareholders' meeting devoted to development of an anti-crisis program-in the framework of the company under examination and analyze all its components. 2) Imagine a model of a speaker (staff, shareholders, suppliers, customers) according to the plan: a sphere of professional activity, social and role attributes, a level of education, a possible reaction to the speaker's: informing about staff reduction (listeners-staff); request to defer payments (listeners-suppliers); persuading in changing the monetary and trade matrix (listeners-the shareholders); persuading in a need to purchase product /goods, etc. (listeners-consumers).

In addition, within this matrix, students make professional speeches. For example, prepare a discourse forming the given matrix (a speech of a company representative to a PR category in a crisis situation-choose your own topic: revocation of a license for providing...services, change of terms of payment for supplies, informing 
customers about the company activities in case of force majeure, etc.).

Discursive matrix and corresponding exercises, as well as methods of discourse analysis are described in more detail in the works of Zorina and Maslennikova (2014).

\section{Conclusion}

Currently at forums (especially at outbound tourism forums) employers, note good theoretical training of graduates, specializing in the tourism sector, but indicate insufficient level of practical skills. Formation of communicative and professional competence of students is so methodically urgent and is such a difficult theoretical and practical problem for higher education institutes. In this regard, not only the role of special subjects increases, but also the role of social and humanitarian disciplines, including speech studies disciplines. To develop a culture of the Russian speech, especially to form professional culture of communication, it is necessary to substantially build on the achievements of modern linguo-pragmatic theory, in particular the theory of discourse and discourse-analysis, this will give a better methodical organization of teaching speech studies disciplines, in the first place, will increase interest of students in learning, significantly improve its results and contribute to a higher degree of readiness of students to professional work, development of his/her communicative competence, to greater development of intelligence and culture in general.

\section{References}

Abdurasulov, D., Yefimova, L., \& Kiriyenkova, Z. (2014). Adaptive Tourism as a Means for Integration in Cultural Environment for the Individuals with Disabilities. World Applied Sciences Journal, 30 $\begin{array}{lllll}\text { (Management, } & \text { Economics, } & \text { Technology } & \text { 3 } & \text { Tourism), }\end{array}$ http://dx.doi.org/10.5829/idosi.wasj.2014.30.mett.19

Kortunov, V. (2013). Prolegomena to the methodology of verification of irrational systems. World Applied Sciences Journal, 22(8), 1180-1194. http://dx.doi.org/10.5829/idosi.wasj.2013.22.08.13010

Krasnova, O., \& Poddubnaya, Y. (2014). Tourism as Socially Welcomed Means of Reality Widening. World Applied Sciences Journal 30 (Management, Economics, Technology \& Tourism), 45-46. http://dx.doi.org/10.5829/idosi.wasj.2014.30.mett.23

Zorina, N., \& Kortunov, V. (2014). The issues of methodology of a discourse-analysis in teaching of professional speech to the students of non-philological specialties. Middle-East Journal of Scientific Research, 19(4), 554-559. http://dx.doi.org/10.5829/idosi.mejsr.2014.19.4.21006

Zorina, N., \& Maslennikova, E. (2014). Formation of Intellectual Competence of Students Studying in the Field of "Tourism". World Applied Sciences Journal 30 (Management, Economics, Technology \& Tourism), 214-215. http://dx.doi.org/10.5829/idosi.wasj.2014.30.mett.53

\section{Copyrights}

Copyright for this article is retained by the author(s), with first publication rights granted to the journal.

This is an open-access article distributed under the terms and conditions of the Creative Commons Attribution license (http://creativecommons.org/licenses/by/3.0/). 